\title{
A hidden culprit for ventricular dysfunction in aortopulmonary window repair: Anomalous origin of left coronary artery. Case report and review of literature
}

\author{
Adnan Alhadlaq, MD, FRCPC, FAAP, ${ }^{\mathrm{a}}$ Santokh Dhillon, MD, FRCPC, \\ From the ${ }^{\mathrm{a}}$ Division of Pediatric Cardiology, Department of Pediatrics, and ${ }^{\mathrm{b}}$ Division of Pediatric Cardiac Surgery, \\ IWK Health Centre, Dalhousie University Faculty of Medicine, Halifax, Nova Scotia, Canada. \\ Disclosures: Authors have nothing to disclose with regard to commercial support. \\ Received for publication April 14, 2016; revisions received July 11, 2016; accepted for publication July 16, 2016; \\ available ahead of print Aug 28, 2016. \\ Address for reprints: Arif Hussain, MD, Division of Pediatric Cardiology, Department of Pediatrics, IWK Health \\ Centre, Dalhousie University, 5850/5980 University Ave, Halifax, Nova Scotia B3K 6R8, Canada (E-mail: arif. \\ hussain@iwk.nshealth.ca). \\ J Thorac Cardiovasc Surg 2016;152:e123-6 \\ $0022-5223 / \$ 36.00$ \\ Copyright (C) 2016 by The American Association for Thoracic Surgery \\ http://dx.doi.org/10.1016/j.jtcvs.2016.07.055
}

Camille L. Hancock-Friesen, MD, FRCSC, FACS, ${ }^{b}$ and Arif Hussain, MD, ${ }^{a}$ Halifax, Nova Scotia, Canada

Video clip is available online.

We report a case of intraoperative diagnosis of an anomalous left coronary artery (LCA) arising from pulmonary artery (ALCAPA) causing severe ventricular dysfunction after aortopulmonary window (APW) repair and present a review of the literature regarding this rare association. Early intraoperative recognition and modification of the repair permitted immediate recovery of cardiac function.

\section{CLINICAL SUMMARY}

A term male infant born after a pregnancy complicated by gestational diabetes and smoking was noted to have a systolic murmur and mild cyanosis after delivery. Echocardiography showed a moderate atrial septal defect shunting left to right, bicuspid aortic valve, right ventricular hypertrophy, and pulmonary arterial hypertension. The infant was seen 3 months later in congestive heart failure. Repeated echocardiography showed a new finding of a dilated right ventricle. The patient was transferred to our facility for further management.

Physical examination revealed mild tachypnea, mild cyanosis, single S2, prominent ejection click, a loud harsh systolic ejection murmur over the left sternal border and mild hepatomegaly. Echocardiography revealed a large type I APW not seen previously (Figure 1, A). Ventricular

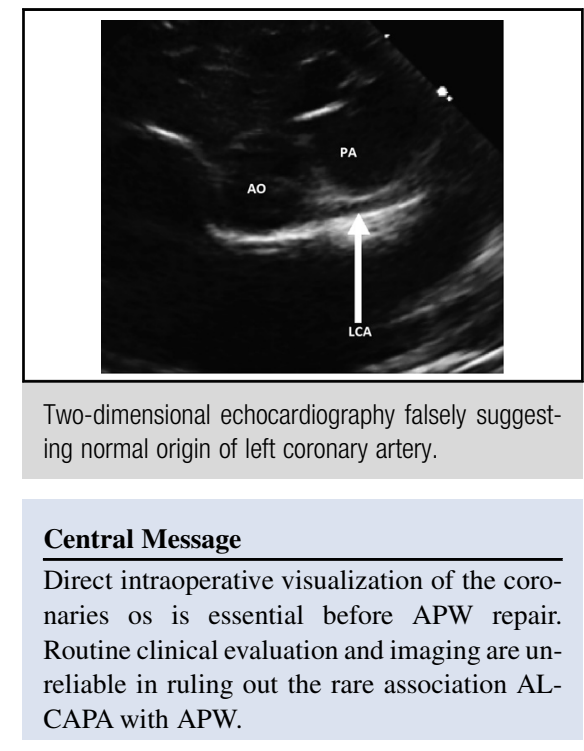

See Editorial Commentary page e127. function was normal, and the coronary artery anatomy appeared normal (Figure 1, B).

Transaortic APW repair was performed through a vertical aortotomy, with a polytetrafluoroethylene patch used to close the defect. Active inspection of the LCA ostium was not undertaken, because the LCA was predicted to originate significantly inferior to the truncal septum and its epicardial course was normal. During attempted weaning from cardiopulmonary bypass, intraoperative transesophageal echocardiography demonstrated severely depressed left ventricular function with normal blood flow in the right coronary artery but minimal flow in the LCA.

The initial aortotomy was reopened, and the patch was taken down for inspection of the coronary ostium. Only the right coronary artery ostium was found to arise from the usual aortic sinus. Inspection through an anterior vertical pulmonary arteriotomy revealed that the ostium of the LCA arose from the pulmonary side of the aortopulmonary septum in the right pulmonary sinus (Figure 1, C and $D)$. 

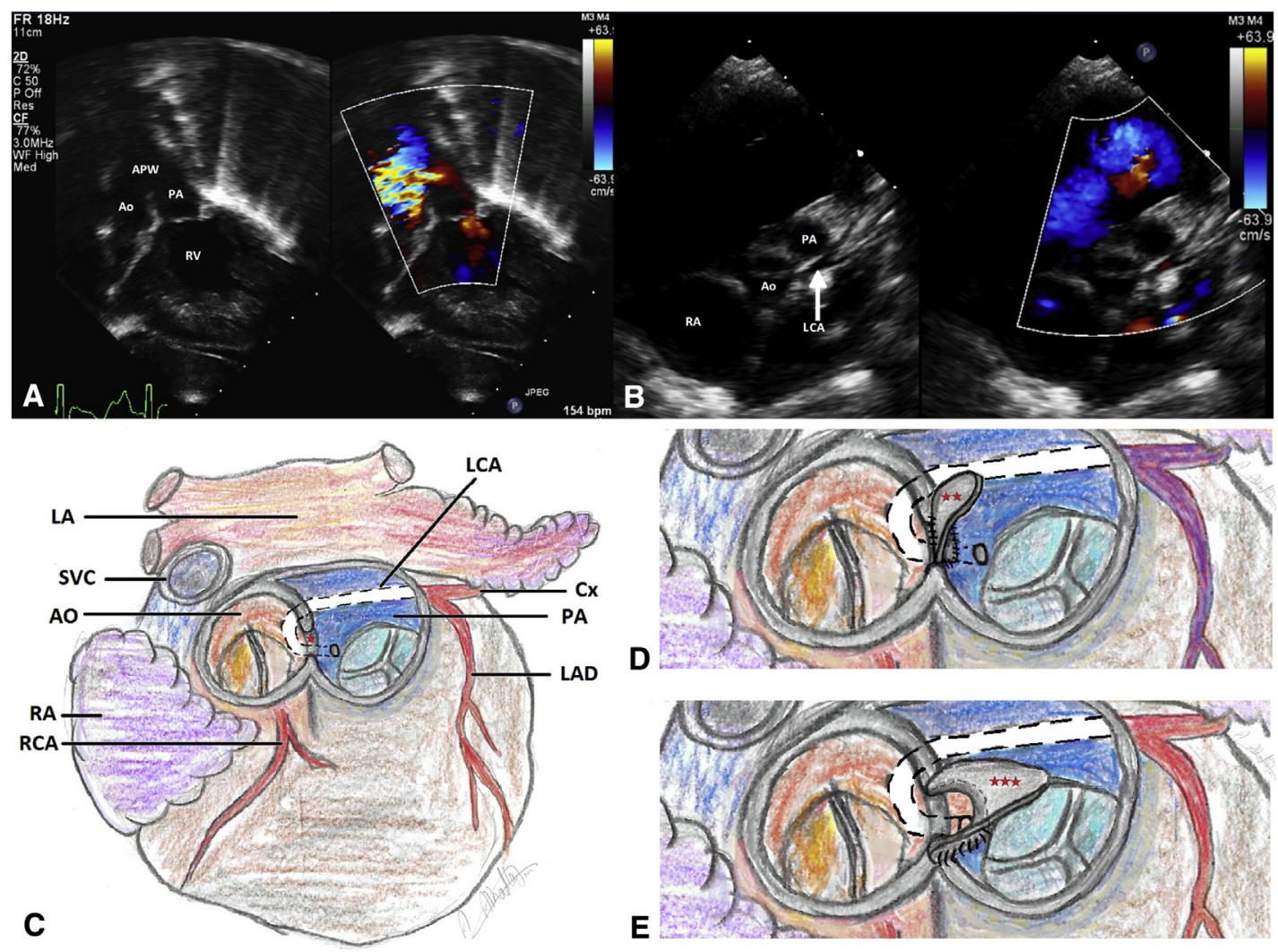

FIGURE 1. A and B, Preoperative echocardiographic views. A, Subcostal coronal view showing large aortopulmonary window $(A P W)$ type I. B, Parasternal short-axis view showing apparent normal origin of the left coronary artery ( $L C A)$ from the aorta (Ao, white arrow). C through E, Diagrammatic illustrations of the heart viewed from above showing the anomalous origin (ostium) and course of the left coronary artery (dotted lines) in relation to the surgical repair. C, Preoperative anatomy showing the aortopulmonary window (single red star) with the left coronary artery ostium originating from the left-facing sinus of the pulmonary valve with the left coronary artery coursing adjacent to the left aortic sinus and then to the left posterior to the pulmonary artery ( $P A$ ) and following the usual course. D, After initial patch (2 red stars) closure of aortopulmonary window leaving the left coronary artery origin from the pulmonary artery. E, Postoperative view after revision of repair and creating a baffle (3 red stars) to incorporate the left coronary artery ostium into the systemic circulation. $R V$, Right ventricle; $R A$, right atrium; $L A$, left atrium; $S V C$, superior vena cava; $C x$, circumflex coronary artery; $L A D$, left anterior descending coronary artery; $R C A$, right coronary artery.

A new baffle repair incorporating the LCA ostium into the systemic circulation was constructed by securing the superior margins of the patch to the superior margin of the APW. The baffle was then extended into the right pulmonary sinus around the LCA ostium. This eliminated the need to mobilize or transfer the origin of LCA and ensured secure coronary flow. Left ventricular function normalized immediately, and the patient remains free of symptoms with normal ventricular function at 24 months of follow-up.

\section{DISCUSSION}

Association of anomalous origin of a coronary artery with APW is exceptionally rare. ${ }^{1}$ Myocardial ischemia, left ventricular dysfunction, and other manifestations seen in isolated ALCAPA do not develop, because the left ventricle is perfused with highly oxygenated blood at a high pressure. ${ }^{2}$

To date, 16 cases of APW in association with anomalous origin of left coronary arteries have been published, including 11 cases of ALCAPA (Table 1). In all but one case, diagnosis was made either intraoperatively or postmortem. The single patient with the preoperative diagnosis of ALCAPA with APW also had tetralogy of Fallot and a coronary artery anatomy initially assessed as normal. ${ }^{6}$ In this case, the patient had severe hypoxia develop in association with ischemic changes on electrocardiogram in the preoperative period, which prompted careful reevaluation of the coronaries leading to the diagnosis.

In our case, the 2-dimensional echocardiography, color Doppler, and initial intraoperative visual inspection without confirming ostial origin suggested normal 
TABLE 1. Aortopulmonary window associated with anomalous left coronary arteries described in the literature

\begin{tabular}{|c|c|c|c|c|c|}
\hline Reference & Associated anomalies & Age & Sex & Circumstances of ALCAPA detection & Outcome \\
\hline Léobon $^{1}$ & ALCAPA & $7 \mathrm{mo}$ & M & Detected intraoperatively & Survived \\
\hline Corno $^{3}$ & ALCAPA & $8 \mathrm{mo}$ & M & $\begin{array}{l}\text { Diagnosed intraoperatively, suspected on } \\
\text { catheterization angiography }\end{array}$ & Survived \\
\hline Doty $^{4}$ & ALCAPA & NA & NA & Missed before repair, leading to ischemia & Deceased \\
\hline Bourlon $^{5}$ & ALCAPA, ASD & $9 \mathrm{mo}$ & M & $\begin{array}{l}\text { Missed on angiography and detected during surgical } \\
\text { dissection }\end{array}$ & Survived \\
\hline McMahon $^{6}$ & ALCAPA, TOF & $3 \mathrm{wk}$ & $\mathrm{F}$ & $\begin{array}{l}\text { Detected by echocardiography after desaturation and } \\
\text { ST-segment depression }\end{array}$ & Survived \\
\hline Kiran $^{7}$ & ALCAPA, TGA & $3 \mathrm{mo}$ & $\mathrm{F}$ & NA & NA \\
\hline Agius $^{8}$ & ALCAPA, VSD, RAA & $2 \mathrm{mo}$ & M & Suspected after cardiac catheterization & Deceased \\
\hline Faulkner $^{9}$ & ALCAPA, VSD, PA, RAA & Neonate & NA & Missed on angiography with postmortem diagnosis & Deceased \\
\hline Morell $^{10}$ & Anomalous LCA from RPA, TOF & Neonate & M & $\begin{array}{l}\text { Missed during cardiac catheterization, detected } \\
\text { during surgical repair }\end{array}$ & Survived \\
\hline Kutsche $^{11}$ & $\begin{array}{l}\text { ALCAPA, TA, VSD, ASD, bicuspid pulmonary } \\
\text { valve, anomalous subclavian artery, PDA }\end{array}$ & $6 \mathrm{wk}$ & M & NA & Deceased \\
\hline McMahon $^{12}$ & $\begin{array}{l}\text { Anomalous LCA from RPA, IAA type B, BAV, } \\
\text { discontinuous PAs }\end{array}$ & $\begin{array}{l}\text { Preterm, } \\
33 \text { wk GA }\end{array}$ & $\mathrm{F}$ & $\begin{array}{l}\text { Detected intraoperatively, echocardiography falsely } \\
\text { showed normal LCA site }\end{array}$ & Survived \\
\hline Chopra $^{13}$ & Aberrant circumflex coronary from MPA & $15 \mathrm{y}$ & $\mathrm{F}$ & $\begin{array}{l}\text { APW diagnosed at } 13 \mathrm{~d} \text {, repaired at } 13 \mathrm{mo} \text {; coronary } \\
\text { anomaly detected at } 15 \mathrm{y} \text { by angiography after } \\
\text { ischemia }\end{array}$ & Survived \\
\hline Mahadevan $^{14}$ & Aberrant circumflex coronary from MPA & $5 \mathrm{mo}$ & M & Detected intraoperative & Survived \\
\hline Hauck $^{15}$ & $\begin{array}{l}\text { LAD and circumflex from RCA with second LAD } \\
\text { MPA providing dual supply, TA, TGA, PAt, VSD, } \\
\text { small RV }\end{array}$ & Neonate & M & $\begin{array}{l}\text { Abnormal coronaries suspected preoperative and } \\
\text { diagnosed intraoperatively }\end{array}$ & Survived \\
\hline Lloyd $^{16}$ & $\begin{array}{l}\text { Right and left coronary ostia originated from the } \\
\text { right PA sinus, VSD, RAA, anomalous left } \\
\text { subclavian from LPA }\end{array}$ & $6 \mathrm{wk}$ & M & Missed coronary anomaly despite catheterization & Deceased \\
\hline Shore $^{2}$ & $\begin{array}{l}\text { Single coronary ostia, TOF, PAt, suprapulmonary } \\
\text { stenosis, VSD }\end{array}$ & $23 \mathrm{y}$ & M & Detected intraoperatively & Survived \\
\hline
\end{tabular}

ALCAPA, Anomalous left coronary artery origin from a pulmonary artery; $N A$, not available; $A S D$, atrial septal defect; TOF, tetralogy of Fallot; TGA, transposition of the great arteries; $V S D$, ventricular septal defect; $R A A$, right aortic arch; $P A$, pulmonary artery; $L C A$, left coronary artery; $R P A$, right pulmonary artery; $T A$, tricuspid atresia; $P D A$, patent ductus arteriosus; $I A A$, interrupted aortic arch; $B A V$, bicuspid aortic valve; $G A$, gestational age; $M P A$, main pulmonary artery; $A P W$, aortopulmonary window; $L A D$, left anterior descending coronary artery; $R C A$, right coronary artery; $P A t$, pulmonary atresia; $R V$, right ventricle; $L P A$, left pulmonary artery.

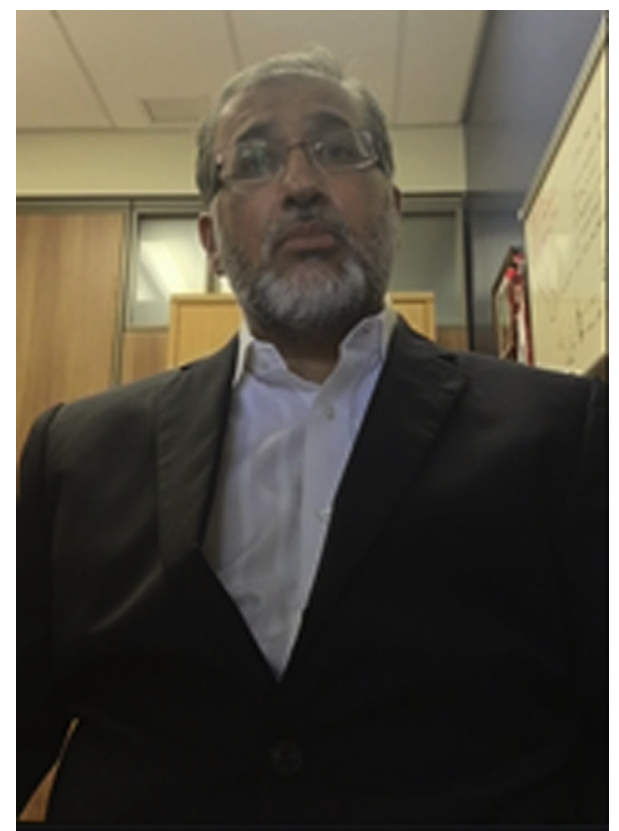

coronary anatomy (Figure 1, B). Clearly, echocardiography may not be reliable in ruling out anomalous origin of coronary arteries, especially ALCAPA, in association with APW (Video 1). The rare occurrence of these lesions, the absence of ventricular dysfunction, the diverse anomalous coronary artery anatomy, and the turbulent flow across the APW make preoperative diagnosis extremely challenging on routine clinical evaluation and imaging. Furthermore, even the normal origin of right and left coronary arteries cannot rule out anomalous origin of the circumflex branch of the LCA. ${ }^{13,14}$ Coronary angiography can be helpful but may fail to demonstrate anomalous coronary artery anatomy clearly in these

VIDEO 1. A.H. explaining the importance of the association of anomalous origin of the left main coronary artery from a pulmonary artery with aortopulmonary window and how this case report highlights issues pertaining to perioperative management and planning. Video available at: http://www.jtcvsonline.org/article/S0022-5223(16)30875-3/addons. 
patients. ${ }^{4}$ We suspect that computed tomographic angiography would have similar limitations. Short of exploring the orifice of the coronaries and carefully tracing their epicardial course to the origin, the diagnosis of anomalous coronary origin may be missed.

Unlike previous reports, in our case, ALCAPA was recognized soon after APW repair, and normal ventricular function was regained after restoration of LCA flow through modification of the repair. This case underlines the importance of careful intraoperative confirmation of ostial origin of the major coronary arteries before the surgical closure of APW. It also adds to the literature a possible mechanism for development of poor ventricular function after the repair of such lesions.

\section{References}

1. Léobon B, Le Bret E, Roussin R, Kortas C, Ly M, Sigal-Cinqualbre A, et al. Technical options for the treatment of anomalous origins of right or left coronary arteries associated with aortopulmonary windows. J Thorac Cardiovasc Surg. 2009; 138:777-8.

2. Shore DF, Ho SY, Anderson RH, de Leval M, Lincoln C. Aortopulmonary septal defect coexisting with ventricular septal defect and pulmonary atresia. Ann Thorac Surg. 1983;35:132-7.

3. Corno A, Pierli C, Lisi G, Biagioli B, Grossi A. Anomalous origin of the left coronary artery from an aortopulmonary window. J Thorac Cardiovasc Surg. 1988; 96:669-71.

4. Doty DB, Richardson JV, Falkovsky GE, Gordonova MI, Burakovsky VI. Aortopulmonary septal defect: hemodynamics, angiography, and operation. Ann Thorac Surg. 1981;32:244-50.

5. Bourlon F, Kreitmann P, Jourdan J, Grinneiser D, Schmitt R, Dor V. Anomalous origin of left coronary artery with aortopulmonary window-a case report with surgical correction and delayed control. Thorac Cardiovasc Surg. 1981;29:91-2.

6. McMahon CJ, Prendiville T, Nolke L. Pre-operative identification of an anomalous left coronary artery from the pulmonary artery in association with tetralogy of Fallot and an aortopulmonary window. Cardiol Young. 2013;24:170-1

7. Kiran VS, Singh MK, Shah S, John C, Maheshwari S. Lessons learned from a series of patients with missed aortopulmonary windows. Cardiol Young. 2008; 18:480-4.

8. Agius PV, Rushworth A, Connolly N. Anomalous origin of left coronary artery from pulmonary artery associated with an aorto-pulmonary septal defect. $\mathrm{Br}$ Heart J. 1970;32:708-10.

9. Faulkner SL, Oldham RR, Atwood GF, Graham TP Jr. Aortopulmonary window, ventricular septal defect, and membranous pulmonary atresia with a diagnosis of truncus arteriosus. Chest. 1974;65:351-3.

10. Morell VO, Feccia M, Cullen S, Elliott MJ. Anomalous coronary artery with tetralogy of Fallot and aortopulmonary window. Ann Thorac Surg. 1998;66: 1403-5.

11. Kutsche LM, Van Mierop LH. Anatomy and pathogenesis of aorticopulmonary septal defect. Am J Cardiol. 1987;59:443-7.

12. McMahon CJ, DiBardino DJ, Undar A, Fraser CD Jr. Anomalous origin of left coronary artery from the right pulmonary artery in association with type III aortopulmonary window and interrupted aortic arch. Ann Thorac Surg. 2002;74: 919-21.

13. Chopra PS, Reed WH, Wilson AD, Rao PS. Delayed presentation of anomalous circumflex coronary artery arising from pulmonary artery following repair of aortopulmonary window in infancy. Chest. 1994;106:1920-2.

14. Mahadevan C, Kareem S, Jitendra V, Sivakadaksham N, Kumar MN. Pulmonary origin of circumflex artery in aortopulmonary window. Asian Cardiovasc Thorac Ann. 2003;11:80-1; discussion 81-2.

15. Hauck A, da Cruz EM, Jaggers J, Jone PN. Tricuspid atresia associated with truncus arteriosus versus aortopulmonary window: combining fetal and postnatal echocardiography to make the diagnosis. Echocardiography. 2013;30: E336-9.

16. Lloyd TR, Marvin WJ Jr, Lee J. Total anomalous origin of the coronary arteries from the pulmonary artery in an infant with aorticopulmonary septal defect. Pediatr Cardiol. 1987;8:153-4. 